\title{
CARACTERIZAÇÃO DO DESEMPENHO DE CRIANÇAS COM DISLEXIA DO DESENVOLVIMENTO EM TAREFAS DE ESCRITA
}

\section{CHARACTERIZATION OF PERFORMANCE OF CHILDREN WITH DEVELOPMENTAL DYSLEXIA IN WRITING TASKS}

Andréa Carla Machado ${ }^{1}$

Simone Aparecida Capellini ${ }^{2}$

Machado AC; Capellini SA. Caracterização do desempenho de crianças com dislexia do desenvolvimento em tarefas de escrita. Rev. Bras. Cresc. e Desenv. Hum. 2011; 21(1): 132-138.

\section{Resumo:}

Introdução: a dislexia do desenvolvimento é caracterizada pelo prejuízo em leitura e escrita de palavras simples, frequentemente envolvendo déficits na decodificação fonológica, soletração que acomete indivíduos sem deficiências sensoriais, isentos de comprometimento emocional significativo e com oportunidades educacionais adequadas. Objetivo: caracterizar o desempenho em atividades relacionadas à escrita observadas em crianças com dislexia do desenvolvimento. Método: participaram deste estudo seis crianças de ambos os sexos, do $3^{\circ}$ ao $7^{\circ}$ ano escolar, alunos de escolas públicas de uma cidade do interior do Estado de São Paulo, com idades de oito a treze anos. Os dados foram coletados no CEES - Centro de Estudos de Educação e Saúde da UNESP - Campus de Marília, SP em tarefas de escrita. Os resultados foram analisados de forma descritiva pela pontuação obtida em porcentagem de acertos. Resultados: as crianças com dislexia do desenvolvimento apresentaram alterações em relação às atividades: Escrita de palavras isoladas e Escrita de palavras ditadas, posicionando-se aquém do esperado para escolaridade, apresentando trocas fonológicas e ortográficas. Conclusão: é importante que crianças com queixas escolares façam uma avaliação mais específica referente a essas tarefas.

Palavras-chave: dislexia; crianças; escrita.

1 Mestre e Doutoranda em Educação Especial pela Universidade Federal de São Carlos - UFSCar; membro do Grupo de Pesquisa “Linguagem, Aprendizagem, Escolaridade” da Universidade Estadual Paulista - UNESP - campus Marília. Bolsista - FAPESP. Endereço: Rua Rui Barbosa, 416 - Centro - CEP: 15120-000 - Neves Paulista - SP. E-mail: decamachado@gmail.com

2 Professora Livre-Docente em Linguagem Escrita do Departamento de Fonoaudiologia e do Programa de Pós-Graduação em Educação da UNESP - Campus de Marília. Líder do Grupo de Pesquisa CNPq "Linguagem, Aprendizagem, Escolaridade”. Correspondência para: Andréa Carla Machado. E-mail: decamachado@gmail.com - Endereço: Rua Rui Barbosa, 416 Centro - CEP: 15120-000 - Neves Paulista - SP.

Pesquisa realizada no Centro de Estudos de Educação e Saúde - CEES/FFC/UNESP - campus- Marília - SP. 


\begin{abstract}
:
Introduction: developmental dyslexia is characterized by impairment in reading and writing of simple words often involving deficits in phonological decoding and spelling. It affects individuals without sensory disabilities, free of significant emotional commitment and adequate educational opportunities. Objective: to characterize the performance in activities related to writing observed in children with developmental dyslexia. Method: a total of six children (boys and girls) from 3rd to 7th grade from public schools in a city in the state of Sao Paulo, eight to thirteen years of age, participated in this study. Data were collected in CEES - Centro de Estudos de Educação e Saúde of UNESP - in Marília -SP in writing tasks. The results were analyzed descriptively by the score in percentage of correct answers. Results: children with developmental dyslexia presented alterations in relation to the activities: writing of isolated words and writing of dictated words were below expectations for the education level, presenting phonological and orthographic changes. Conclusion: it is important that children with school problems make a more specific evaluation concerning these tasks.
\end{abstract}

Key words: dyslexia; children; writing.

\section{INTRODUÇÃO}

AA dislexia do desenvolvimento é caracterizada pelo prejuízo em leitura de palavras simples freqüentemente envolvendo déficits na decodificação fonológica, soletração que acomete indivíduos sem deficiências sensoriais, isentos de comprometimento emocional significativo e com oportunidades educacionais adequadas ${ }^{1}$.

Os componentes da rede funcional envolvidos no processamento fonológico e atribuídos ao giro inferior frontal direito e esquerdo e cerebelo foram comparados em bons leitores e disléxicos. Para os leitores disléxicos, as conexões funcionais entre o giro frontal inferior esquerdo com as regiões direitas do frontal, occipital e cerebelar estavam interrompidas, estando relacionadas à falha de decodificação de palavras².

A dislexia é uma herança familial, portanto hereditária e de causa neurobiológica. Uma história da família é um dos mais importantes fatores na identificação da dislexia, pois entre 23 e $65 \%$ das crianças com pais disléxicos apresentaram dificuldades em leitura, eviden- ciando que a identificação pode ser realizada precocemente Os genes ligados à dislexia estão localizados nos cromossomos 2, 3, 6, 15 e 18, indicando uma herança poligênica, deixando ainda incertas as diferentes manifestações cognitivas pelo fenótipo ou os subtipos de dislexia $^{3,4}$.

Além do prejuízo no processamento fonológico também estão comprometidos elementos subjacentes a leitura e escrita, como por exemplo, atenção, habilidade narrativa, velocidade de leitura em razão da dificuldade em lidar com símbolos gráficos, capacidade de desenvolver temática textual e coerência o que influenciam na contagem, recontagem e compreensão de histórias, bem como estratégias inadequadas de interação com o texto e inferências ${ }^{5}$.

As falhas na escrita das crianças disléxicas compreendem, na maioria, estruturas lingüísticas similares àquelas encontradas em crianças de desenvolvimento típico: no entanto, mostram-se persistentes, aparecendo com mais freqüência e prevalência ${ }^{6}$.

No entanto, os reflexos das dificuldades ortográficas $^{7}$ vividas pelas crianças disléxicas 
costumam ser mais extensos do que na leitura, já que, além da exigência cognitiva imposta pela própria escrita, o português é menos transparente para escrita do que para a leitura ${ }^{8}$.

Provavelmente $^{9}$, o processo de conversão fonológico-ortográfica, isoladamente, seja insuficiente para a obtenção da correta ortografa de palavras. Assim, os erros podem indicar a presença de déficits no processamento ortográfico, pois certamente, as características psicolingüísticas (como freqüência, regularidade, por exemplo) das palavras interferem no aprendizado e desempenho ortográficos. Sabe-se, também que a escrita de transparência ortográfica pode ser caracterizada pela correspondência direta entre o fonema e o grafema, independentemente das regras de contexto.

Portanto, a análise da escrita pode fornecer importantes informações sobre a real capacidade da criança em associar a letra ao som correspondente. Estas informações, analisadas separadamente daquelas que se referem ao uso de outras regras ortográficas, podem ser úteis para a compreensão do aprendizado da leitura e da escrita.

Com base no exposto, este estudo teve por objetivo caracterizar o desempenho de crianças com dislexia do desenvolvimento em tarefas de escrita.

\section{MÉTODO}

Este estudo foi realizado após a aprovação do Comitê de Ética em Pesquisa da Faculdade Filosofia e Ciências da UNESP - campus de Marília -SP, sob o protocolo n ${ }^{\circ}$ 1589/2008.

Participaram deste estudo seis escolares com diagnóstico de dislexia do desenvolvimento com idade de 8 a 13 anos e ambos os sexos, cursando a $3^{\circ}$ a $7^{\circ}$ ano de escolas públicas municipal de uma cidade de médio porte situada no interior do Estado de São Paulo. Os dados foram coletados no CEES - Centro de Estudos de Educação e Saúde da UNESP - campus de
Marília- SP, onde os participantes foram diagnosticados por uma equipe interdisciplinar. As tarefas de escrita Foram: Conceito de escrita, Escrita livre de palavras, Escrita ditadas de palavras.

A coleta de dados teve início após a assinatura do Termo de Consentimento Livre e Esclarecido pelos responsáveis das crianças. Os resultados foram analisados de forma descritiva pela pontuação obtida em porcentagem de acertos em cada tarefa. Ressalta-se que, para a análise da porcentagem das tarefas de escrita representadas nos gráficos da figura 1 foi adotada um escala de conceitos, os quais estão descritos a seguir.

80-100 = muito satisfatório;

60-80 = satisfatório;

40-60 = conceito razoável;

20-40 = insatisfatório

0-20 = muito insatisfatório

Os requisitos para os Critérios de inclusão foram: Crianças com acuidade visual e auditiva e desempenho cognitivo dentro dos padrões da normalidade - descritos em prontuários do CEES; crianças com risco para dislexia do desenvolvimento comprovada pela avaliação do CEES; Nunca terem participado de programas de intervenção fonoaudiológica, pedagógica ou neuropsicológica.

Os requisitos para os Critérios de exclusão foram: Crianças que apresentaram acuidade visual e auditiva e desempenho cognitivo abaixo dos padrões da normalidade - descrição em prontuários; síndromes genéticas ou outras síndromes; Deficiência auditiva; Deficiência visual; Deficiência Mental.

\section{Procedimento realizado com tarefas relacionadas à escrita}

Na tarefa de conceitos de escrita, foi solicitado a criança identificar dezesseis conceitos (a frente do livro, onde ler, onde começa a ler, para que direção seguir, o significado dos sinais de pontuação, entre outros). Na tarefa de escrita livre de palavras, era solicitado 
para a criança escrever o maior número de palavras que conhecesse em uma folha em branco durante o tempo de cinco minutos. Na tarefa de escrita das palavras ditadas, era solicitada a criança que escrevesse quatro palavras (uma monossílaba, uma dissílaba, uma trissílaba e uma polissílaba), escolhidas de uma lista de palavras e duas frases simples.

\section{Resultados}

A figura 1 apresenta as porcentagens de acertos das crianças disléxicas nas tarefas de escrita.

Observa-se que na tarefa Conceito de escrita as crianças apresentaram um conhecimento prévio sobre essa tarefa. Pois, as escolares com dislexia DL1, DL2, DL3 apresentaram 85\% de acerto na tarefa de Conceito de escrita indicando um domínio muito satisfatório.

No entanto, as crianças disléxicas DL5 e DL6 apresentaram um domínio muito satisfatório na tarefa Conceito de escrita com porcentagem de acerto de 93\%, no qual a criança DL4 também obteve um domínio satisfatório

Na tarefa Escrita de palavras isoladas verifica-se que há uma porcentagem razoável de acertos em todas as crianças avaliadas. É importante ressaltar que tal resultado pode estar relacionado com a evidência no déficit na memória de trabalho e na atenção dessas crianças.

Observa-se que $50 \%$ das crianças avaliadas na tarefa Escrita de palavras isoladas obtiveram porcentagens de acertos diferenciadas. A criança DL1 teve um domínio insatisfatório. A criança DL2 obteve 56\% tendo um domínio razoável da tarefa. Já a criança DL3 apresentou na mesma tarefa de Escrita livre de palavras um domínio $65 \%$ indicando um domínio razoável da tarefa.

Em relação ainda a tarefa Escrita de palavras isoladas as crianças com dislexia que DL5 e DL6 obtiveram acertos de $87 \%$ e $72 \%$, respectivamente, um domínio muito satisfatório e satisfatório em relação à tarefa. O aluno DL4 obteve uma porcentagem acima de $90 \%$ indicando domínio muito satisfatório em relação à tarefa.

Na tarefa escrita de palavras ditadas as crianças DL2 e DL3 obtiveram acerto de 50 e $60 \%$ indicando um domínio razoável diante da tarefa. No entanto, observamos que a criança DL1 na tarefa de Escrita palavras ditadas apresentou um acerto de $90 \%$ indicando um domínio muito satisfatório para essa tarefa.

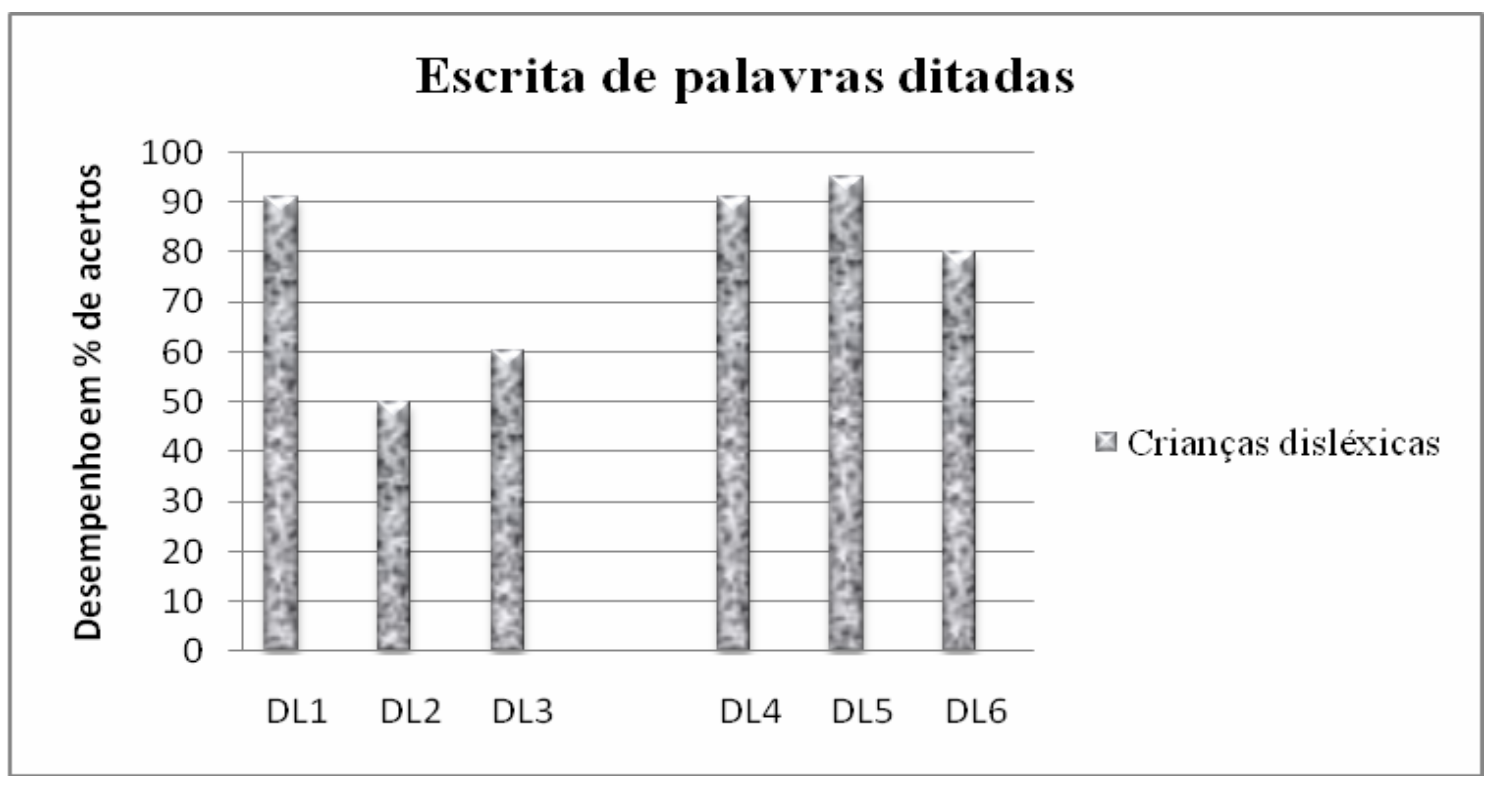




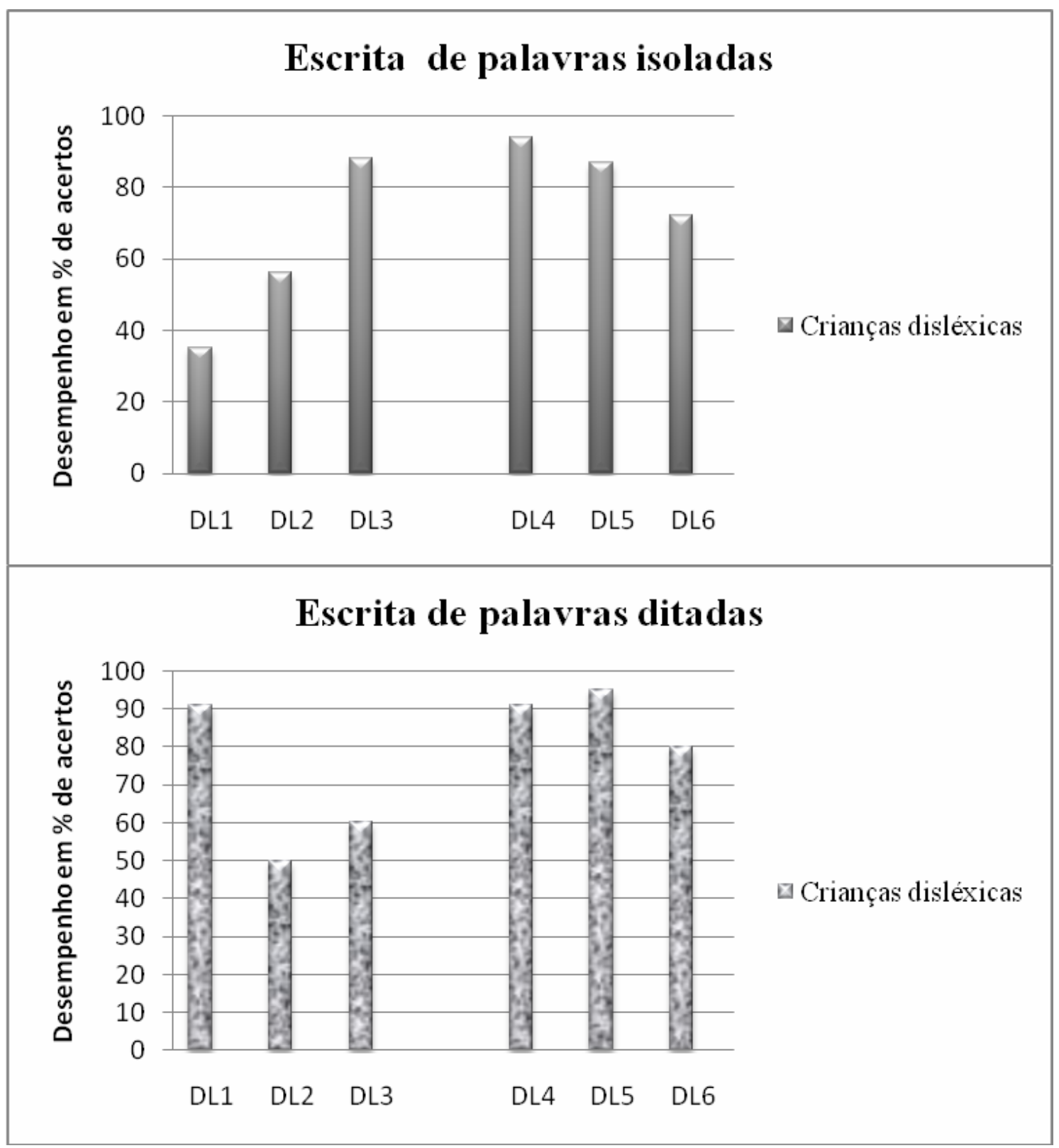

Figura 1: Desempenho das crianças disléxicas nas Tarefas de escrita

As crianças DL3, DL4 e DL5 apresentaram acerto de $90 \%$ indicando um domínio muito satisfatório da tarefa Escrita de palavras ditada.

Observamos também que as crianças com dislexia do desenvolvimento apresentaram alterações em relação às atividades: Escrita de palavras isoladas e Escrita de palavras ditadas posicionandose aquém do esperado para escolaridade, apresentando trocas fonológicas e ortográficas.

\section{DISCUSSÃO}

Nas tarefas de escrita Conceito de escrita, Escrita de palavras isoladas e Escrita ditada, as crianças avaliadas apresentaram resultados diversos dentro da mesma condição.

Esses achados do estudo apontam para diferenças individuais compensatória das crianças com dislexia, pois é sabido que na ausência dos tipos de códigos fonológicos - seu dé- 
ficit, outras estratégias de compensação são desenvolvidas. ${ }^{10,11}$

Outro ponto importante que merece ser destacado nos achados das tarefas escritas é em relação a uma visão qualitativa sobre esses resultados. Em uma maioria, as crianças disléxicas obtiveram uma média no domínio satisfatório perante as tarefas, ou seja, considerando os critérios na análise não apresentaram dificuldades ponderando os déficits encontrados nesse distúrbio.

Esses resultados vão ao encontro dos estudos que indicam os fatores interlingüísticos ${ }^{12}$ como responsáveis pelas diferenças encontradas em pesquisas realizadas em algumas línguas - diferenças na regularidade ou transparência da sua ortografia. Até certo ponto, as abordagens didáticas refletem a natureza da tarefa a ser aprendida, e existem evidências crescentes de que as demandas da aprendizagem da leitura e escrita diferem entre os idiomas, português (considerado um idioma transparente) e inglês (idioma opaco), por exemplo. No entanto, hoje se sabe que existem diferenças na facilidade com a qual as crianças adquirem as habilidades de aptidão entre os idiomas. Assim, leitores disléxicos que falam o português (um idioma transparente) obtêm sucesso no uso de algumas habilidades alfabéticas com palavras regulares, como encontradas nesse estudo, por exemplo.

Os estudos nessa vertente nos lembram que, embora o principal sinal da dislexia seja, freqüentemente, um problema de leitura, o déficit na escrita é mais adequadamente considerado uma das várias manifestações comportamentais possíveis de que um déficit cognitivo subjacente. Obviamente, uma importante fonte de variação nestas manifestações comportamentais é a natureza da ortografia que a criança disléxica está aprendendo. ${ }^{8,9,13}$

No entanto, também observamos nos resultados do presente estudo discrepâncias no acerto das tarefas escritas. Nessa perspectiva, deve-se considerar que a apropriação do sis- tema de escrita é um processo evolutivo no qual o aprendiz vai elaborando hipóteses ou idéias a respeito do que é a escrita, as quais revelam diferentes graus de conhecimentos que estão sendo constituídos. Isto significa que não se aprende a escrever de imediato e que "erros" estão implícitos em tal processo ${ }^{6}$.

De acordo com a literatura ${ }^{13}$ crianças com dislexia apresentam problemas no processamento da memória de trabalho, ou seja, um conjunto de habilidades cognitivas que permite que informações novas e antigas sejam manipuladas com o objetivo de realizar determinada tarefa.

Dessa forma, as crianças com dislexia do desenvolvimento apresentam dificuldades freqüentemente no controle da atenção cujo componente pode ser evidenciado nos resultados da presente pesquisa.

\section{CONCLUSÃO}

A proposta do estudo foi caracterizar o desempenho de crianças com dislexia do desenvolvimento em tarefas de escrita. Foram encontradas alterações fonológicas e ortográficas, nas tarefas de escrita de palavras isoladas e escrita de palavras ditadas.

A partir dos aspectos apontados, podemos considerar que os resultados deste estudo têm implicações práticas para prevenção, principalmente, focando o as tarefas de escrita como atividades importantes para auxiliar na preparação de intervenções que visem diminuir o fracasso de crianças que apresentarem dislexia do desenvolvimento. Pois, a literatura sugere que a experiência escolar das crianças com dislexia do desenvolvimento, quando enriquecidas com atividades propícias ao desenvolvimento de estratégias podem possibilitar uma aprimoramento substancial no desenvolvimento dessas habilidades. Dessa forma, é importante que crianças com queixas escolares façam uma avaliação mais específica referentes às essas tarefas. 


\section{REFERÊNCIAS}

1. Snowling MJ, Stackhouse J. Dislexia, fala e linguagem: um manual do profissional. Porto Alegre: Artmed; 2004.

2. Stanberry LI, Richards TL, Berninger VW, Nandy RR, Anlward, EH, Maravilla KR, Stock, PS, Cordes D. Low frequency signal changes reflect differences in functional connectivity between good readers and dyslexics during continuous phoneme mapping. Magnetic Resonance Imaging. 2006; 24: 217-229.

3. Capellini AS. Desempenho em consciência fonológica, memória operacional, leitura e escrita na dislexia familial. Pró-Fono Revista de Atualização Científica. 2007; 19(4): 374-380.

4. Galaburda AM, Cestnick L. Dislexia del desarrollo. Revista de Neurología. 2003; 36(1):3-9.

5. Salgado CA. Programa de remediação fonológica em escolares com dislexia do desenvolvimento. [Dissertação] Campinas: Faculdade de Ciências Médicas, Universidade Estadual de Campinas; 2005.

4. Shaywitz S. Entendendo a dislexia: um novo e complete programa para todos os níveis de problemas de leitura. Porto Alegre: Artmed; 2006.

5. Snowling MJ Dyslexia as a phonological deficit: evidence and implications. Child Psychology \& Psychiatry Review.1998; 3(1).
6. Zorzi JL, Ciasca SM. Caracterização dos erros ortográficos em crianças com transtorno de aprendizagem. CEFAC. 2008; 10(3): 321-331.

7. Mousinho, R, Correa J, Mesquita F. Perfil da escrita da criança disléxica. In: Capovilla FC. Transtornos de aprendizagem: progressos em avaliação e intervenção preventiva e remediativa. São Paulo: Memnon, 2010.

8. Kellogg RT, Olive T, Piolat A. Verbal, visual, and special working memory in written language production. Acta Psychologics. 2006. 124(3), 382-297.

9. Dias RS, Ávila CRB. Uso e conhecimento ortográfico no transtorno especifico de leitura. Revista da Sociedade Brasileira de Fonoaudiologia. 2008. 13(4), 381-190.

10. Olson RK, Davidson BJ, Kliegel R, Davies SE. Development of phonetic memory in disabled and normal readers. Journal of Experimental Child Psychology. 1984; 37; 187-206.

11. Rack J. P. Ortographic and phonetic coding in normal and dyslexic reading. Bristish Journal of Psychology. 1985;76; 325-340.

12. Cossu G. Biological constraints on literacy acquisition. Reading and Writing.1999;11; 213-237.

13. Swanson HL. Jerman O. The influence of working memory on reading growyh in subgroups of chidren with reading disabilities. Journal Experimental Child Psychology. 2007;96: 249-283.

Recebido em: 10/ago./10

Modificado em: 09/dez./10

Aceito em: 28/dez./10 